\title{
Breakdown in assortative mating leads to hybrid swarm in pygmy angelfishes
}

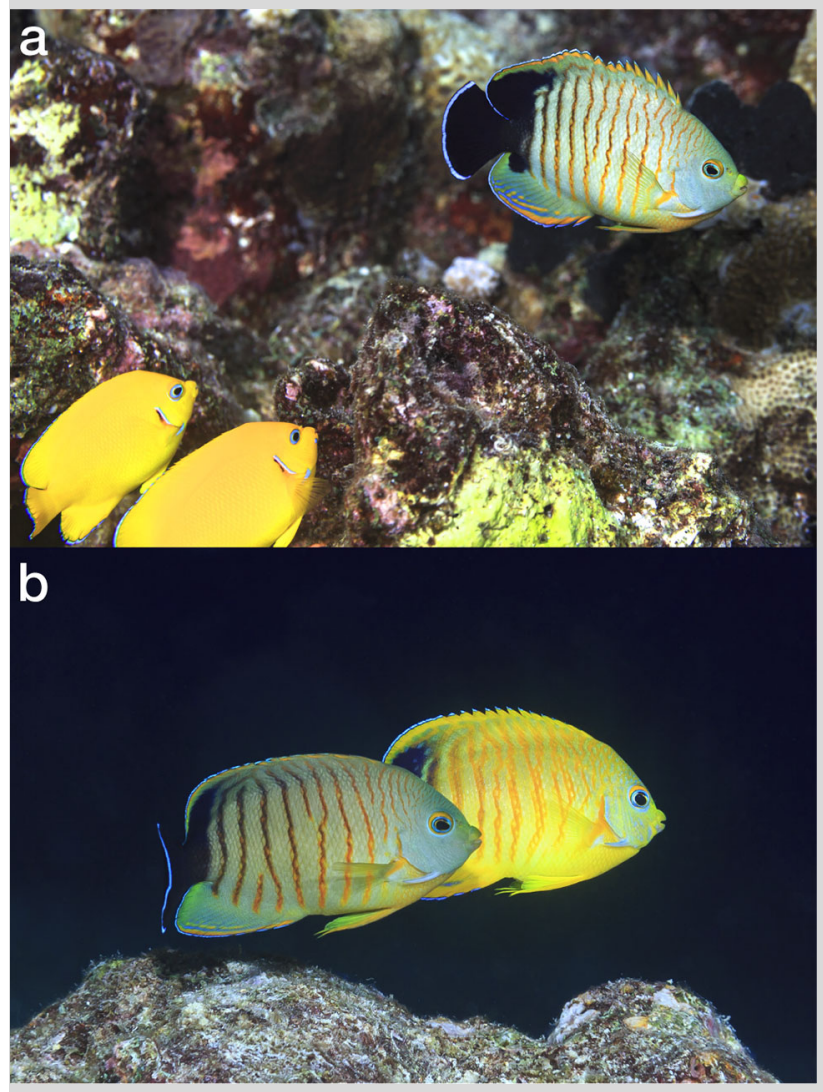

Fig. 1 a A male Centropyge eibli (right) displaying to $C$. flavissima females (left) minutes before spawning with them. b A male $C$. eibli (left) and a female C. flavissima $\times$ C. eibli hybrid (right) at the start of their spawning ascent
Hybridisation is widespread in coral reef taxa (Richards and Hobbs 2015); however, the processes leading to interbreeding are poorly understood. A breakdown in assortative mating is commonly implicated in hybridisation of reef fishes, and although mixed-species groups are often recorded, interbreeding is rarely observed (Hobbs and Salmond 2008). Interbreeding could occur unintentionally (accidental hybridisation), or through the deliberate actions of one (sneak spawning) or both parent species (disassortative mate choice).

Molecular studies reveal a history of hybridisation among pygmy angelfishes (DiBattista et al. 2016). These fishes form discrete harems comprised of one large male and multiple smaller females. During field trips to Christmas Island (Indian Ocean) in September 2015, April 2016 and June 2017, we observed interbreeding between Centropyge flavissima, C. eibli and C. vrolikii. We visited 19 mixed-species harems and observed the male courted and then sequentially spawned with each of the females in his harem (Fig. 1a; electronic supplementary material, ESM). Across the harems we observed every mating combination involving males and females of each species and their hybrids (Fig. 1b: ESM).

The mixed-species harems we observed have been stable (same location and harem members) for 1-6 yrs. Monitoring of six harems revealed interbreeding occurred on consecutive days and across multiple years. We conclude that members of the mixed-species harems repeatedly choose to interbreed with other species. Introgression identified in the genes of these three species (DiBattista et al. 2016) can be explained by the ongoing breakdown in assortative mating caused by disassortative mate choice.

\section{References}

DiBattista JD, Gaither MR, Hobbs JPA, Rocha LA, Bowen BW (2016) Angelfishes, paper tigers and the devilish taxonomy of the Centropyge flavissima complex. J Hered 107:647-653

Hobbs JPA, Salmond JK (2008) Cohabitation of Indian and Pacific Ocean species at Christmas and Cocos (Keeling) Islands. Coral Reefs 27:933

Richards ZT, Hobbs JPA (2015) Hybridisation on coral reefs and the conservation of evolutionary novelty. Curr Zool 61:132-145

Electronic supplementary material The online version of this article (https://doi.org/10.1007/s00338-017-1643-0) contains supplementary material, which is available to authorized users.

J. P. A. Hobbs $(\bowtie)$. J. D. DiBattista

Department of Environment and Agriculture, Curtin University, Perth, WA 6845, Australia

e-mail: jp.hobbs@curtin.edu.au

T. H. Sinclair-Taylor

Red Sea Research Center, Division of Biological and Environmental Science and Engineering, King Abdullah University of Science and Technology,

Thuwal 23955, Saudi Arabia

Received: 26 September 2017 / Accepted: 9 November 2017/Published online: 27 November 2017

Coral Reefs (2018) 37:155

(C) Springer-Verlag GmbH Germany, part of Springer Nature 2017

https://doi.org/10.1007/s00338-017-1643-0 